\title{
Co-seismic and post-seismic pore-fluid pressure changes in the Philippine Sea plate and Nankai decollement in response to a seismogenic strain event off Kii Peninsula, Japan
}

\author{
Earl Davis ${ }^{1}$, Keir Becker $^{2}$, Kelin Wang $^{1}$, and Masa Kinoshita ${ }^{3}$ \\ ${ }^{1}$ Pacific Geoscience Centre, Geological Survey of Canada, 9860 W. Saanich Rd., Sidney, B.C. V8L 4B2, Canada \\ ${ }^{2}$ Rosenstiel School of Marine and Atmospheric Science, University of Miami, Miami, Florida 33149, USA \\ ${ }^{3}$ Japan Agency for Marine-Earth Science and Technology, 2-15, Natsushima-cho, Yokosuka-shi, Kanagawa 237-0061, Japan
}

(Received July 28, 2008; Revised October 31, 2008; Accepted November 27, 2008; Online published July 27, 2009)

\begin{abstract}
New pressure data from a pair of Ocean Drilling Program (ODP) hydrologic borehole observatories at ODP Sites 1173 and 808, located off Japan in the subducting Philippine Sea plate and in the nearby Nankai accretionary prism, respectively, show clear signals associated with an earthquake swarm off the Kii Peninsula that began on September 5, 2004, roughly $220 \mathrm{~km}$ away from the observatory sites. At Site 1173, formation pressures rose by $1.0-1.5 \mathrm{kPa}$ at the time of the largest earthquake $\left(M_{\mathrm{w}}=7.5\right)$, then continued to rise to a total anomaly of $4 \mathrm{kPa}$ during the following 200-300 days. These transients are inferred to reflect co-seismic and slow continuing volumetric contraction of the plate by amounts of roughly $0.2 \times 10^{-6}$ and $0.5 \times 10^{-6}$, respectively. The sign of the estimated strain is consistent with that predicted with a seismic-moment-constrained elastic half-space dislocation model, but the amplitude is much larger, by roughly a factor of 6 at the time of the main earthquake, and by nearly a factor of 20 when the total pressure-estimated strain at the end of the post-seismic period is compared to that estimated from the total cumulative seismic moment including aftershocks. The simplest inference that can be drawn is that a large component of aseismic slip occurred in the epicentral area. At Site 808, pressure at the deepest monitoring zone just above the subduction decollement fell at the time of the largest earthquakes. This may reflect shear-induced dilatation which would be consistent with strain- or velocityhardening behaviour along this seaward-most part of the subduction thrust interface.
\end{abstract}

Key words: Co-seismic strain, post-seismic strain, Ocean Drilling Program, CORK borehole observatory.

\section{Background}

In September, 2004, a sequence of earthquakes occurred beneath the Nankai Trough offshore of the Kii peninsula of southwest Japan (Park and Mori, 2005), causing detectable crustal deformation onshore (Ashi et al., 2005; Hashimoto et al., 2005; Imakiire et al., 2006) and very low-frequency (VLF) earthquakes inferred to be in the accretionary prism (Obara and Ito, 2005). The largest events were an $M_{\mathrm{w}}=7.2$ "foreshock" at 2004-09-05 10:07:08 (UTC) and an $M_{\mathrm{w}}=$ 7.5 "main shock" at 14:57:31 the same day. Hypocentral depths place the largest earthquakes within the subducting Philippine Sea plate, and moment-tensor solutions for the largest events indicate thrust motion roughly N-S, parallel to the direction of convergence between the subducting Philippine Sea plate and Japan (Fig. 1(a)). Aftershock activity (Fig. 1(b)), identified with both onshore seismic stations and briefly with a local deployment of ocean-bottom seismometers (Sakai et al., 2005), continued for a year and was distributed over a depth range of about $5-25 \mathrm{~km}$.

In this paper we present data downloaded in August, 2006, and December, 2007, from two Advanced CORK ("Circulation Obviation Retrofit Kit") hydrologic borehole

Copyright (c) The Society of Geomagnetism and Earth, Planetary and Space Sciences (SGEPSS); The Seismological Society of Japan; The Volcanological Society of Japan; The Geodetic Society of Japan; The Japanese Society for Planetary Sciences; TERRAPUB observatories installed in 2001 at Ocean Drilling Program Sites 808 and 1173 (Mikada et al., 2002). The sites are situated near the axis of the Nankai trough, $220 \mathrm{~km}$ from the off-Kii epicentre in a direction perpendicular to the thrust direction of the largest events (Fig. 1(b, c)). The records include formation-fluid pressure signals that reflect local response to the off-Kii seismogenic slip, similar to the response to a strain event originating off Cape Muroto in 2004 (Davis et al., 2006).

\section{New Observations}

Formation and reference seafloor pressures at Sites 808 and 1173 are measured every 10 minutes by gauges at the seafloor, with the formation signals transmitted from multiple permeable screens in the formation via hydraulic tubing. At Site 1173, five screens (numbered at both sites from bottom up) are positioned at depths ranging from 354 to $722 \mathrm{~m}$ below the seafloor (mbsf), with the deepest being at the top of the igneous oceanic crust (Mikada et al., 2002). The records indicate the presence of modest and generally uniform fluid pressure ranging from about +70 to $+85 \mathrm{kPa}$ above hydrostatic (Fig. 2(a)), and, in the more hydrologically confined parts of the section, they display rising secular trends that have been interpreted to be the consequence of accumulating contractional strain of the plate between large subduction-thrust earthquakes, when the inter-plate 
a

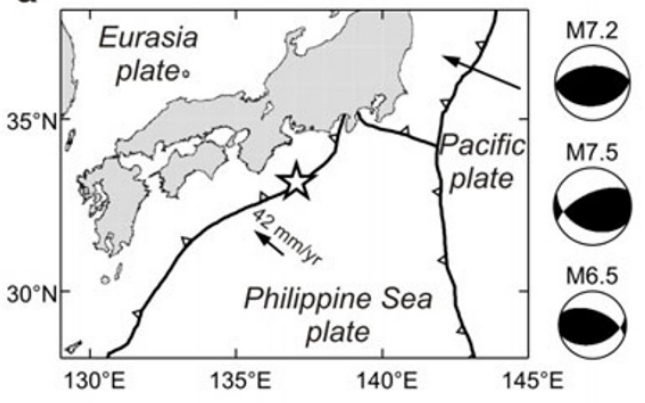

C

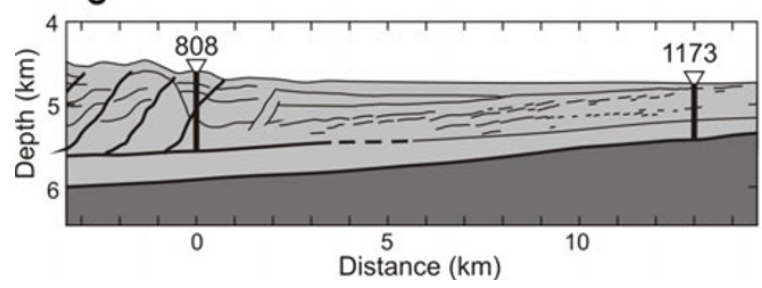

b

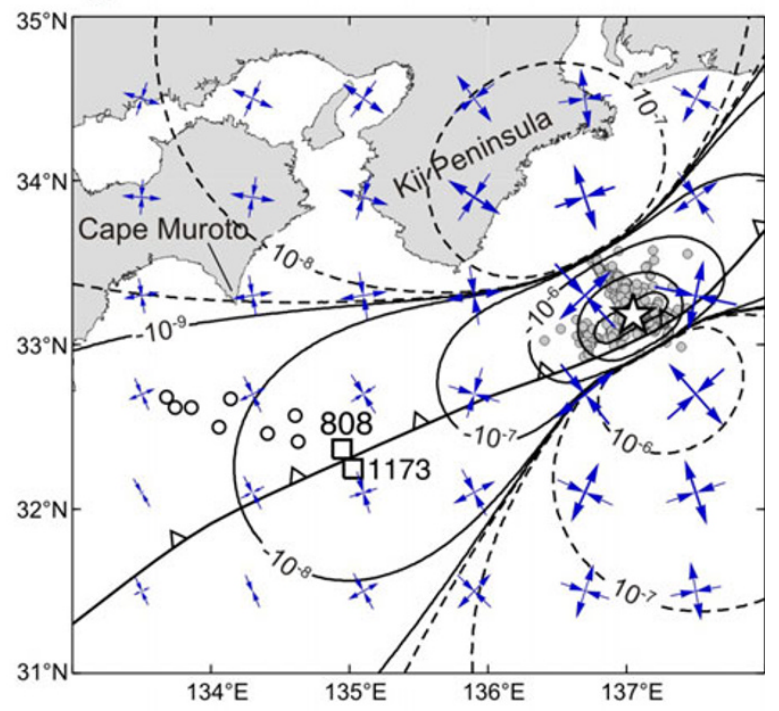

Fig. 1. Maps (a, b) and cross-section (c) of the Nankai Trough, offshore central Japan. Focal mechanisms shown in (a) are those of the three largest earthquakes of September 5th and 6th off Kii Peninsula, 2004. They have nearly the same location as show by the stars in (a) and (b). Aftershocks are shown as small filled circles in (b), along with 2003 VLF earthquakes off Cape Muroto (Obara and Ito, 2005; larger open circles), and locations of CORK borehole observatory Sites 808 and 1173. Volumetric strain near the seafloor (contours in b) and horizontal strain (logarithmically scaled arrows) have been estimated using a standard dislocation model of a rectangular fault in a uniform elastic half-space (Okada, 1992; see Explanatory Notes section for details). A similar pattern of strain would have been generated by a dislocation centered in the area of the VLF events; in that case, the borehole sites would fall in the seaward dilatational lobe. The schematic cross section in (c) shows the locations of the borehole at Site 808 that extends through the frontal thrust of the Nankai accretionary prism to the level of the decollement, and the hole at Site 1173 that penetrates to igneous basement (dark grey).
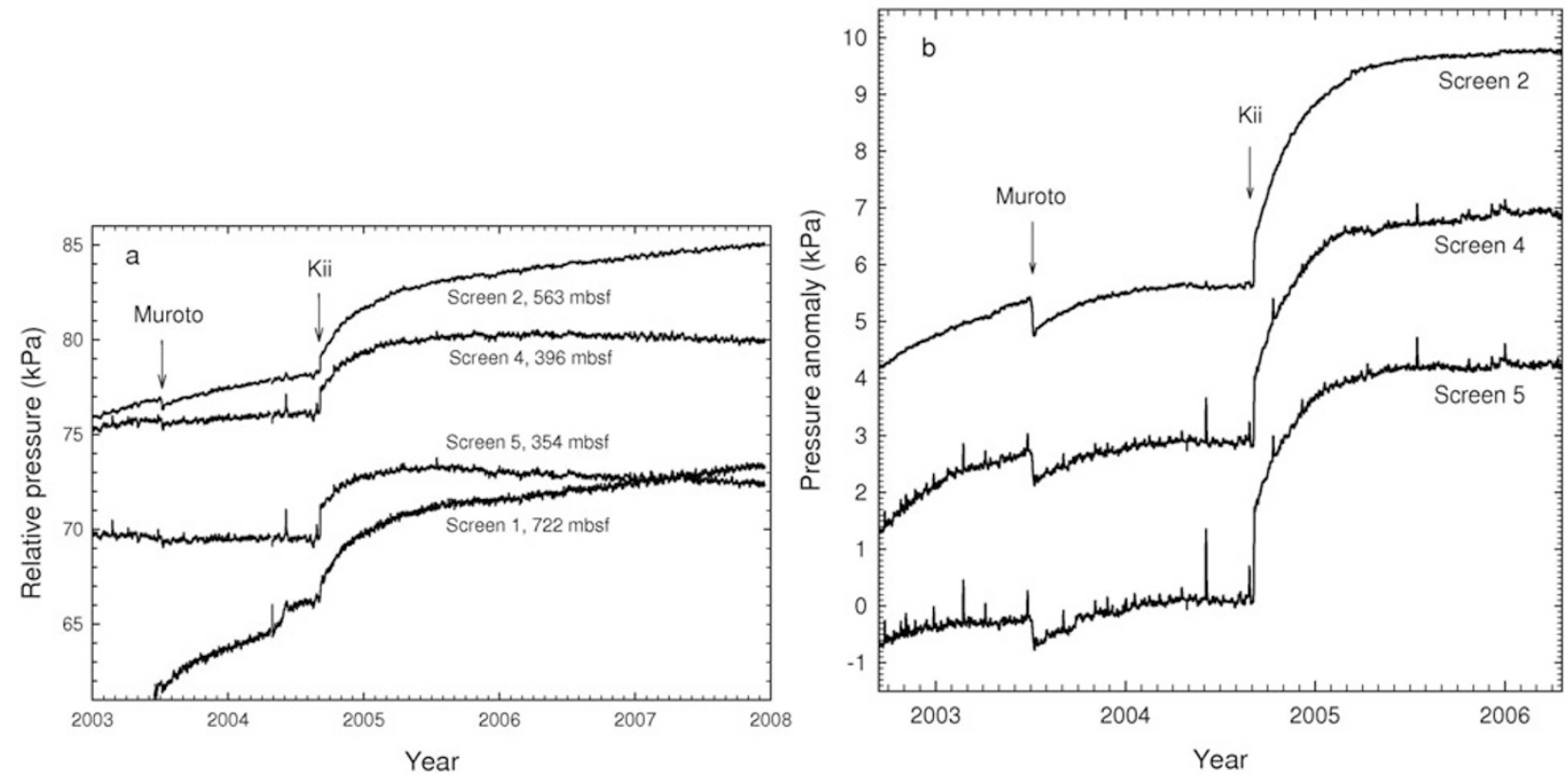

Fig. 2. CORK formation pressure records from ODP Site 1173 (location in Fig. 1). Pressures in (a), including basement screen 1, have had effects of seafloor loading removed and are plotted relative to hydrostatic pressure. Records from screens within the sediment section in (b) are plotted at an expanded scale, with long-term linear trends removed.

subduction interface is locked (Davis et al., 2006). Superimposed on these trends are two offsets, a previously described negative step at the time of a swarm of very low frequency earthquakes off Cape Muroto in 2003 (Davis et al., 2006), and a positive step at the time of the 2004 off-Kii earthquakes (Fig. 2(b); also visible in Fig. 2(a)). Because of the relatively large pressure sampling interval (10 minutes), the co-seismic strain caused by the main off-Kii event is not defined in detail, although filtered strain-seismograms from terrestrial borehole strain-meter sites show a "slow" onset of deformation, beginning at the time of the $P$-wave arrival and reaching full offset roughly $45 \mathrm{~s}$ later (Okubo et al., 2005). The greatest co-seismic changes in pressure seen at Site $1173(1.0-1.5 \mathrm{kPa})$ occurred at the time of the largest 


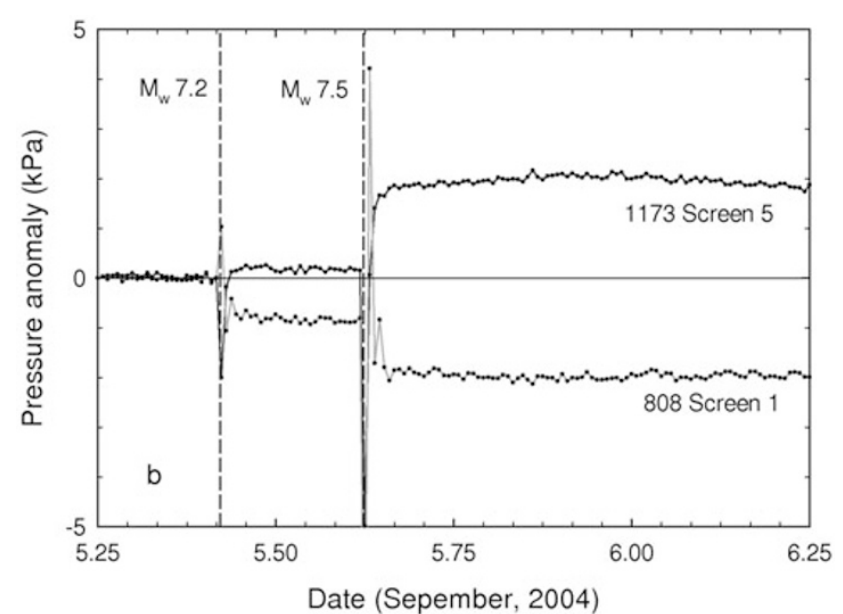

Fig. 3. Expanded views of formation-pressure records from Sites 1173 (Philippine Sea plate) and 808 (Nankai decollement) at the time of the first large earthquakes off Kii Peninsula. Individual co-seismic steps are discriminated in these records. While highly aliased by the 10 minute sampling period, surface wave or tsunami signals are captured with the first datum after each of the earthquakes.

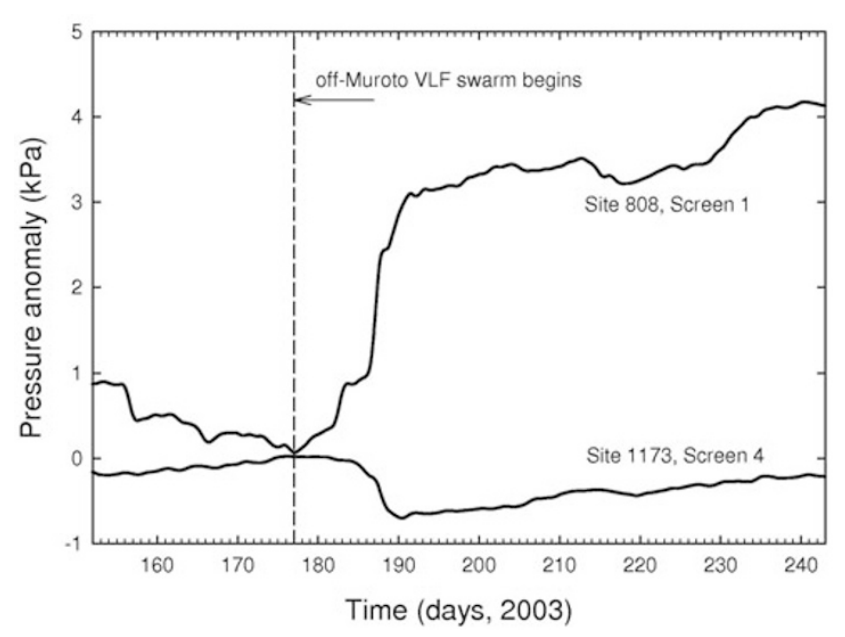

Fig. 4. Expanded views of formation pressure records from Sites 1173 and 808 at the time of the VLF earthquake swarm off Cape Muroto.

earthquake, although a very small step of consistent sign is resolved at one of the screens $(0.2 \mathrm{kPa}$ at screen 5$)$ at the time of the first earthquake as well (Fig. 3). While similar to the steps seen at the time of the VLF swarm off Cape Muroto (Fig. 4), the off-Kii steps occur more quickly and are opposite in sign. Following the off-Kii step-wise coseismic changes in pressure, a long-term rise is witnessed, well above the secular trends present at each level. Trendremoved pressure anomalies stabilize in 200-300 days at levels roughly $4 \mathrm{kPa}$ higher than pre-seismic baseline values (Fig. 2(b)). A long-term transient also appears to follow the off-Muroto event.

The CORK at Site 808 has six screens at depths of 371 , 533, 787, 833, 879, and 922 mbsf. The deepest is believed to be partially open to the seafloor because operational difficulties at the time of installation precluded installation of a bridge plug designed to seal the inner diameter of the CORK casing (Mikada et al., 2002). Only sed-

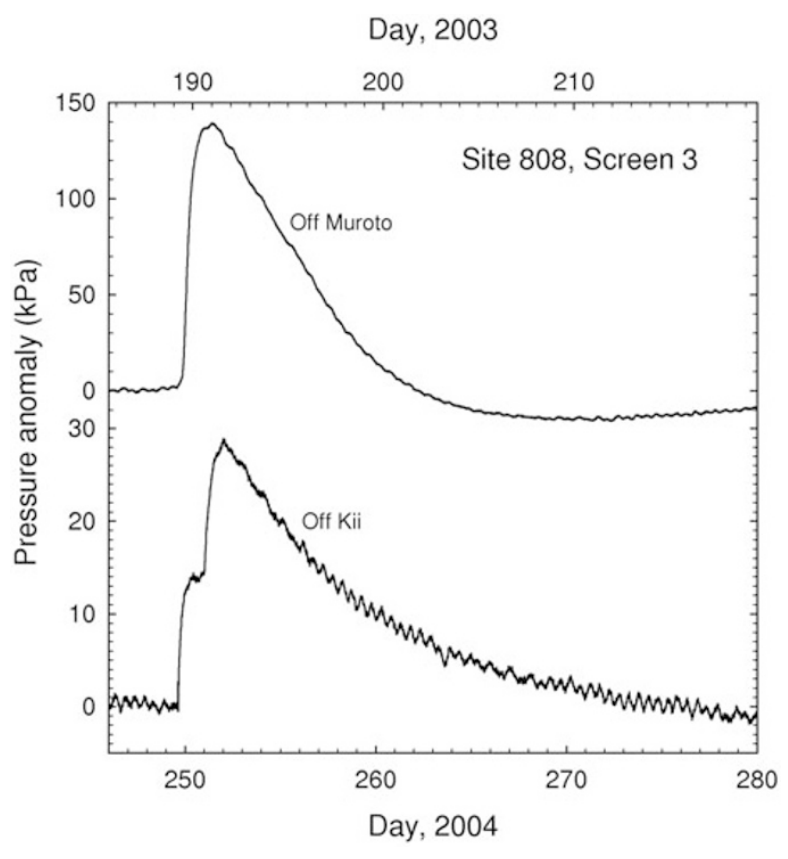

Fig. 5. Transients observed in the sediment section above the decollement at Site 808 (screen 3) at the times of the main off-Kii earthquakes and of the VLF earthquake swarm off Cape Muroto. These transients, which are largest in the least permeable parts of the section, are believed to be a consequence thermal expansion of confined water in the CORK screens and umbilical tubing caused by transient up-hole flow of warm water inside the unsealed casing from the relatively permeable decollement.

iment that may have accumulated in the bottom part of the casing can provide any resistance to flow, and the degree to which the modest overpressure observed at that level (c. $30 \mathrm{kPa}$ at the time of the off-Muroto and off-Kii events) reflects the natural state of the formation is unknown. At the upper five screens, impulsive transients of varying amplitudes occurred immediately following the off-Kii seismic events. These are very similar to ones observed at the time of the off-Muroto VLF swarm event (Fig. 5) which were previously interpreted to reflect strain associated with a migrating dislocation on the decollement (Davis et al., 2006). In consideration of other observations at this site and the physical characteristics of the installation, a more likely explanation has emerged that these transients are not a direct indication of strain, but rather a consequence of thermal expansion of confined fluid in the CORK plumbing, screens, and surrounding sediment caused by pulses of water flowing from the level of the decollement up the inside of the unsealed casing at the times of the events (Davis and Becker, 2007). We suspect that leakage from the overpressured decollement through fill in the deeper part of the casing may have been temporarily augmented by strain- or shaking-enhanced permeability (e.g., Elkhoury et al., 2006). Slightly warmer water brought up by transient vertical flow would cause thermal expansion of water in the surrounding formation and within the hydraulic umbilical, and wherever screens are imbedded in sufficiently low-permeability material, the expansion-induced pressure would not be relieved. This will happen if the hydraulic diffusivity (which can range over orders of magnitude) is less than the thermal diffusivity (about $0.4 \times 10^{-6} \mathrm{~m}^{2} \mathrm{~s}^{-1}$ ). This 
situation exists in the fine-grained lower Shikoku facies, where permeabilities measured on cores are $\approx 10^{-18} \mathrm{~m}^{2}$ (Bourlange et al., 2005; Gamage and Screaton, 2005) and hydraulic diffusivities are indeed less than thermal diffusivity (see discussion below). In this part of the section, strain signals that may be present are probably masked by the dominating thermal overprint. The amplitude of the pulses would provide quantitative constraints on hydraulic diffusivity if the thermal source function were known.

The deepest screen (screen 1 spanning depths from 918 to $926 \mathrm{mbsf}$ ) is situated just above the top of the decollement zone as identified by drilling and logging data (937965 mbsf; Mikada et al., 2002). A negative step-wise coseismic response to each of the two large off-Kii earthquakes is evident there (Fig. 3). An impulsive transient is absent, probably because the relatively high permeability of the decollement zone and the low-resistance hydraulic path in the unsealed casing allow pressure generated by thermal expansion within the screen 1 umbilical to be relieved. The step-wise pressure changes may be a qualitatively correct reflection of strain at this level, although they probably provide only a crude underestimate of the magnitude of strain, given the unknown degree of resistance to leakage through the casing (assumed to be caused by intruded sediment or drilling debris). The change is opposite in sign to the response to the off-Kii event witnessed at Site 1173 (Fig. 3), and opposite to the 808-screen-1 response to the off-Muroto event (Fig. 4).

A longer-term post-seismic pressure anomaly is not seen at this screen, although the lack of the casing seal and limited resistance to flow would probably prohibit any slow variation from being detected. Remedial sealing of the casing has been attempted recently; if successful, this should permit reliable observations of both the average state and transient pressure signals at this level in the future, and eliminate the thermal perturbations at the monitoring screens higher in the section.

\section{First Order Inferences}

With the exceptions noted, we believe the co- and postseismic pressure changes observed at these sites to be caused by local volumetric strain. Other explanations that have been put forward for other co-seismic pressure and water-level transients (e.g., Wang et al., 2001), including the possibilities that signals propagate from remote locations to borehole sites hydrologically or that formation pressure anomalies are the consequence of seismic shaking, are considered unlikely at the Nankai sites.

A hydrologic origin for the pressure transients is ruled out by the low hydraulic diffusivity that characterizes the majority of the sediment section. Linear hydrologic diffusion over a scale length $l$ would take place with a time constant $\tau=l^{2} / \eta^{\prime}$, where $\eta^{\prime}=k / \mu \zeta^{\prime}$ is the 1-D hydraulic diffusivity, $k$ is permeability, $\mu$ is fluid viscosity, and $\zeta^{\prime}$ is the 1-D storage compressibility (Wang, 2004). With $\mu=10^{-3} \mathrm{~Pa} \mathrm{~s}$, and other properties given and determined below, $\zeta^{\prime}$ would be of the order of $10^{-9} \mathrm{~Pa}^{-1}$, and if $k$ were $10^{-18} \mathrm{~m}^{2}$, a value typical of permeabilities measured on sediments sampled from the lower Shikoku facies sediments (Bourlange et al., 2005; Gamage and Screaton,
2005), $\eta^{\prime}$ would be of the order of $10^{-9} \mathrm{~m}^{2} \mathrm{~s}^{-1}$. Signals would propagate by diffusion a distance of only a few $\mathrm{m}$ in a few hundred days, and three-dimensional hydraulic diffusion would be even slower. Given the synchroneity of the signals among the screens and between the sites, we are left to conclude that the signals are generated in the immediate vicinity of the boreholes.

Shaking-induced pore-pressure change is precluded by the difference in response to the two events observed to date: such changes at a given site would be of the same sign for every event. At Site 1173, pressure increased at the time of the off-Kii earthquake swarm, but decreased at the time of the off-Muroto VLF swarm, and at Site 808, screen 1 , pressure fell at the time of the off-Kii event but rose at the time of the off-Muroto event (cf. Figs. 3 and 4). Contrasting senses of co-seismic pressure change have been witnessed in other CORKed seafloor boreholes (e.g., figure 4 in Kastner et al., 2006), and in all documented cases (with the exception of Site 808), the signs are consistent with the local volumetric strain expected according to whether the sites were in contractional or dilatational quadrants of strain generated by the associated earthquakes. Thus, response to static strain, not dynamic, appears to dominate.

The relationship between volumetric strain $\theta$, and instantaneous pore-fluid pressure $P$ in a poroelastic medium can be defined as a function of elastic properties of the fluidsaturated formation by

$$
\theta=\beta_{\mathrm{m}}\left(1 / \gamma-\alpha_{\mathrm{m}}\right) P
$$

where

$$
\begin{aligned}
\alpha_{\mathrm{m}} & =1-\beta_{\mathrm{s}} / \beta_{\mathrm{m}}, \\
\gamma & =\alpha_{\mathrm{m}} \beta_{\mathrm{m}} / \zeta, \\
\zeta & =\alpha_{\mathrm{m}} \beta_{\mathrm{m}}+n \alpha_{\mathrm{f}} \beta_{\mathrm{f}},
\end{aligned}
$$

and

$$
\alpha_{\mathrm{f}}=1-\beta_{\mathrm{s}} / \beta_{\mathrm{f}},
$$

and where $\alpha_{\mathrm{m}}$ is the effective stress coefficient, $\beta_{\mathrm{m}}, \beta_{\mathrm{s}}$, and $\beta_{\mathrm{f}}$ are the compressibilities of the formation matrix and the solid and fluid constituents, respectively, $\gamma$ is the 3-D loading efficiency, $\zeta$ is the 3-D storage compressibility, and $n$ is the porosity (Wang, 2004, and references therein). These relationships allow the sensitivity of pressure to strain to be expressed as a function of matrix compressibility, as shown in Fig. 6 for a range of porosities, assuming $\beta_{\mathrm{s}}=$ $2.0 \times 10^{-11} \mathrm{~Pa}^{-1}$ and $\beta_{\mathrm{f}}=4.0 \times 10^{-10} \mathrm{~Pa}^{-1}$ (at the average temperature of the formation of roughly $50^{\circ} \mathrm{C}$ ). Additional relationships between 1-D (confined, indicated with primes) and 3-D properties,

$$
\begin{aligned}
\beta_{\mathrm{m}}^{\prime} & =\beta_{\mathrm{m}}\left(1+v_{\mathrm{m}}\right) / 3\left(1-v_{\mathrm{m}}\right) \\
\gamma^{\prime} & =\alpha_{\mathrm{m}} \beta_{\mathrm{m}}^{\prime} / \zeta^{\prime} \\
\zeta^{\prime} & =\zeta-\alpha_{\mathrm{m}} \beta_{\mathrm{m}} \varphi
\end{aligned}
$$

with

$$
\varphi=2 \alpha_{\mathrm{m}}\left(1-2 v_{\mathrm{m}}\right) / 3\left(1-v_{\mathrm{m}}\right),
$$




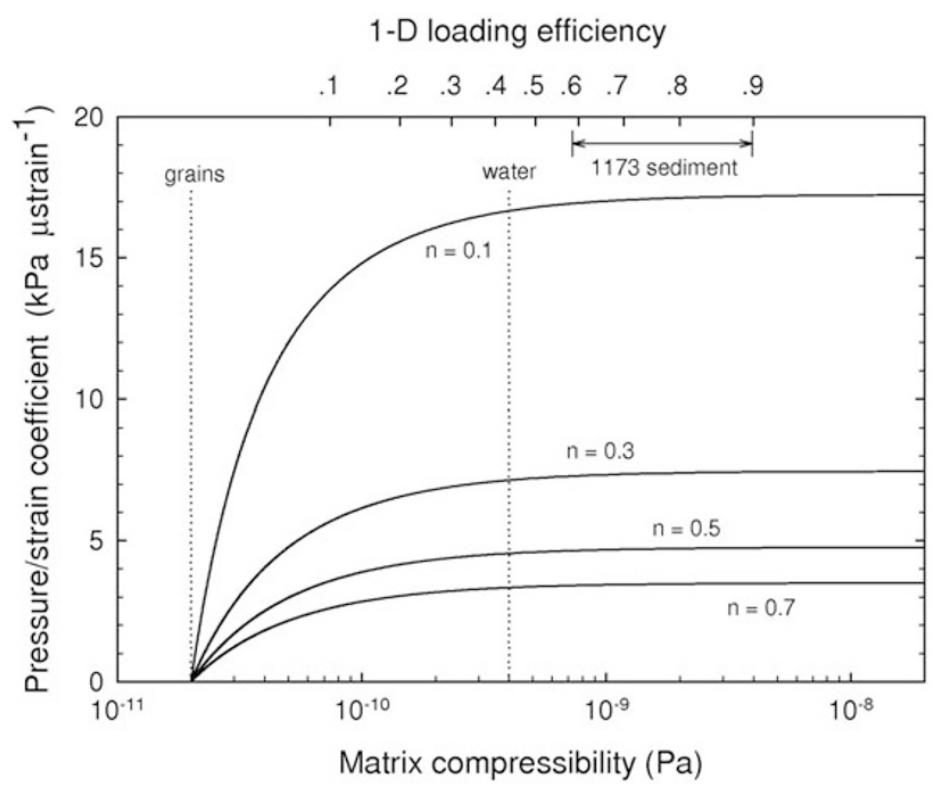

Fig. 6. Undrained strain-to-pressure conversion efficiency as a function of matrix compressibility, 1-D loading efficiency, and porosity, $n$, as outlined in the text. Vertical dotted lines show values of fluid- and solid-constituent compressibility. The observed range of sediment loading efficiency observed at Site 1173 is shown.

allow $\beta_{\mathrm{m}}$ to be constrained by the 1-D loading efficiency $\gamma^{\prime}$, a property constrained by the ratio of formation pressure variation relative to seafloor tidal loading. Application of these relationships, with $n=0.4$ typical for the lower Shikoku facies sediments, and a matrix frame Poisson's ratio for the sediment framework $v_{\mathrm{m}}=0.1$, yields the upper axis shown in Fig. 6. The tidal loading efficiency $\gamma^{\prime}$ observed in the sediment section at Site 1173 varies systematically with depth from 0.9 to 0.6 , suggesting values of $\beta_{\mathrm{m}}$ ranging from $4 \times 10^{-9}$ to $7 \times 10^{-10} \mathrm{~Pa}^{-1}$.

In general, the pressure/strain coefficient is sensitive to $\beta_{\mathrm{m}}, \beta_{\mathrm{f}}, \beta_{\mathrm{s}}$, and $n . \beta_{\mathrm{f}}$ and $\beta_{\mathrm{s}}$ are reasonably well constrained and probably vary little in a section like that penetrated at Site 1173 . $\beta_{\mathrm{m}}$ can vary considerably, but in the case of these semi-consolidated sediments, $\beta_{\mathrm{m}}\left(7 \times 10^{-10}\right.$ to $4 \times$ $\left.10^{-9} \mathrm{~Pa}^{-1}\right)>\beta_{\mathrm{f}}\left(4.0 \times 10^{-10} \mathrm{~Pa}^{-1}\right) \gg \beta_{\mathrm{s}}\left(2.0 \times 10^{-11} \mathrm{~Pa}^{-1}\right)$, so the conversion coefficient is seen to be sensitive only to $n$, which is relatively uniform at 0.4 (Mikada et al., 2002). Thus, a fairly uniform sensitivity of roughly $6 \mathrm{kPa} \mu$ strain $^{-1}$ is suggested (Fig. 6). Greater sensitivity might be expected in the igneous basement, although the strain-related transients seen at screen 1 are no larger than those in the lower Shikoku sediments (Fig. 2). The positive co-seismic pressure steps observed within the sediments at the time of the largest of the off-Kii earthquakes are inferred to reflect contractional volumetric strain of roughly $0.2 \times 10^{-6}$, and the continuing contraction would add about $0.5 \times 10^{-6}$ to this. The co-seismic step-wise decrease at the decollement at Site 808 (Fig. 3) suggests expansional strain of a similar magnitude, although uncertainties associated with the incomplete seal and the poorly defined physical properties precludes a confident estimate.

\section{Discussion}

\subsection{Large co-seismic strain}

Comparison of the co-seismic strain estimated from the pressure change at Site 1173 with that predicted for a dislocation appropriate for the largest off-Kii earthquake (Fig. 1(b)) shows the observed strain to be consistent in sign with that predicted-a robust result that is insensitive to large changes in focal parameters used for the dislocation model-but the magnitude is much greater than expected from the dislocation model (Fig. 7). This contrast in magnitude is similar to contrasts inferred from CORK data in other settings. In the case of far-field observations of a seismogenic seafloor-spreading event at the Juan de Fuca Ridge, it was proposed that co-seismic slip took place with low seismic efficiency, and that the moment determined from radiated seismic energy underestimated the total (Davis et al., 2001). This possibility cannot be excluded in the case of the off-Kii earthquake response, and in both instances, the "missing" moment is very large: roughly $2 \times 10^{16} \mathrm{~N}$ m estimated seismically vs. $4 \times 10^{17} \mathrm{~N}$ m estimated from pressure-derived strain at Juan de Fuca, and $1.7 \times 10^{20}$ vs. $1.1 \times 10^{21} \mathrm{~N}$ m for Nankai off-Kii. Until co-located pressure and strain observations are available (as is planned for future Integrated Ocean Drilling Program boreholes offshore of the Kii Peninsula), the possibility that the borehole pressure signals are somehow amplified cannot be excluded, although no mechanism has been conceived. Heterogeneity is an unlikely explanation, given the consistency in response at each of the screens at Site 1173, and given the consistency in multiple instances of the contrast between observed and expected signals. Presence of the borehole (cased and thus incompliant, or uncased and compliant, relative to the formation) will affect the strain tensor in the surrounding medium, but the balance between radial and azimuthal components leaves volumetric strain unaffected, despite the contrast between the compressibilities of 


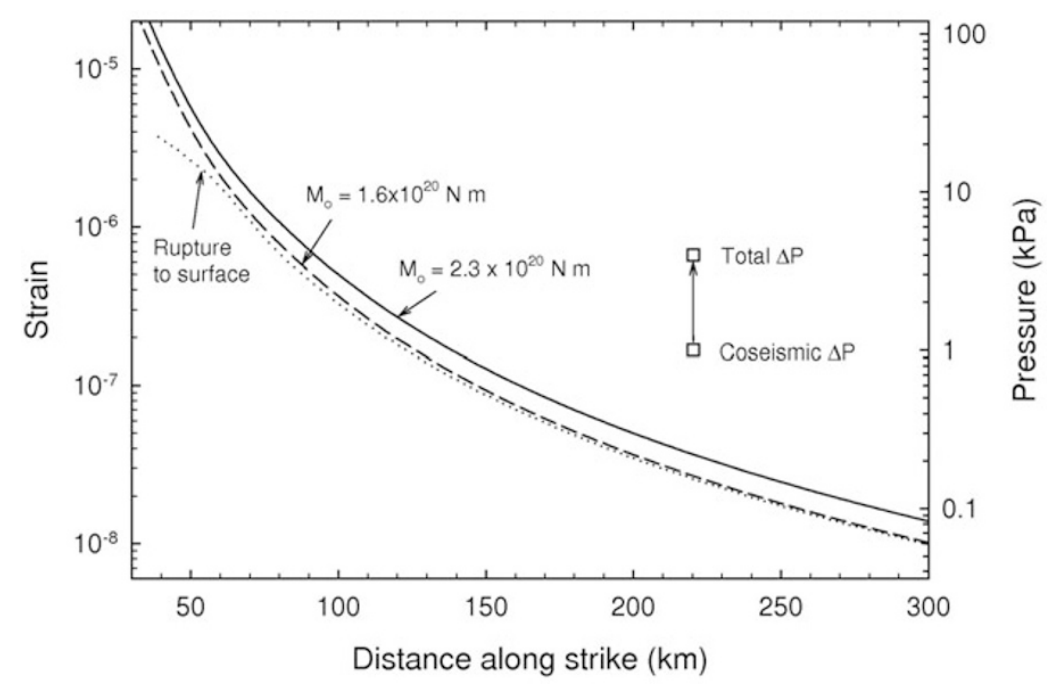

Fig. 7. Profile of predicted strain and consequent fluid pressure along a line running along the Nankai Trough from the off-Kii epicentral area (distance $=0$ ) through the CORK observatory sites (see Fig. 1(b)), along with the range of co-seismic pressure changes at Site 1173 observed immediately after the largest off-Kii earthquake and 8 months later. Estimated profiles are shown for slip moments equal to the seismic moment of the primary off-Kii earthquake (dashed line), and to the total accumulated seismic moment of all earthquakes of the initial swarm and aftershocks (solid line; see Explanatory Notes section for details). The dotted line, showing the strain profile assuming a shallower slip plane that reached the seafloor, demonstrates the insensitivity of far-field strain to the details of slip.

the borehole and formation (Jaeger and Cook, 1969). Partitioning of stresses between the fluid and solid constituents of the formation (the effective loading efficiency) might be affected by drilling disturbances, but drilling-induced damage is most likely to increase porosity and reduce, not enhance, the instantaneous strain-to-pressure conversion coefficient immediately around the casing.

Given these considerations, it seems likely that the largerthan-expected pressure signals are correct and that the seismic moment reflects only part of the total slip moment. Several other observations are consistent with this inference, including the following: 1) Co-seismic strain steps having a character very similar to the pressure steps shown in Figs. 2 and 3 were observed at several borehole strainmeter sites on the Kii Peninsula. Strains at the time of the $M_{\mathrm{w}}=7.5$ event were generally greater than predicted by a dislocation model (by up to a factor of 5; Ashi et al., 2005). 2) The tsunami recorded by two seafloor pressure observatory sites off Cape Muroto was accounted for with a source function having a total slip similar to that suggested by the seismic moment of the $M_{\mathrm{w}}=7.5$ event (Matsumoto and Mikada, 2005), but at both sites the observed arrival was significantly later than their earthquake-timed dislocation model predicted (by 1.5-2 minutes), and it was necessary to extend the dislocation to within $100 \mathrm{~m}$ of the seafloor (much shallower than the seismic data indicate) to match the tsunami waveform and amplitude with the model results. 3) Onshore strong-motion seismographs show lowfrequency waves from the $M_{\mathrm{w}}=7.5$ event that are larger in amplitude and longer in duration than expected (Hayakawa et al., 2005). If rupture were to have extended close to the seafloor, further along strike, and over an extended period of time, all of these observations, including the pressure observations presented here, might be accounted for. Low propagation speed and anomalous displacement could be common within both the upper oceanic crust and overly- ing sediments which possess low shear moduli (Vidale and Houston, 1993; Bilek and Lay, 1999).

\subsection{Post-seismic strain}

Equally noteworthy is the long-term pressure transient and inferred post-seismic strain which grew to an amount two to three times the co-seismic strain over a period of a few months (Fig. 2(b)), with the rate of pressure increase not returning to the pre-seismic rate until roughly a year after the earthquake. Similar long-period strain following the same earthquake was seen in continuous GPS data on Kii Peninsula by Imakiire et al. (2006). The continuing rise in pressure and inferred deformation was contemporary with local very-low-frequency (VLF) earthquakes observed early in the post-seismic period (Obara and Ito, 2005; Nakamula et al., 2008), and with aftershock seismicity in the epicentral area which persisted for more than a year (Fig. 8). A comparison of the aftershock moment history with the post-seismic pressure history suggests a link between the post-seismic slip in the epicentral area and regional strain (Fig. 8). As in the case of the main event, however, the total accumulated moment is much smaller than that suggested by the pressure transient (Fig. 7). Either post-seismic slip in the epicentral region occurred with low seismic efficiency, or much of the long-term strain at the borehole site was the consequence of regional post-seismic deformation associated with a viscoelastic relaxation process like that proposed for post-seismic deformation elsewhere (Hofton and Foulger, 1996; Pollitz et al., 2001; Pollitz, 2005), with higher stresses in the near-field region (Fig. 1(b)) diffusing to more distal areas.

\subsection{Reaction of the decollement to shear}

A third observation that may be significant is that of the negative co-seismic pressure steps witnessed at the level of the decollement at Site 808 at the time of the off-Kii event (Fig. 3) which suggest dilatancy. Given the close mutual proximity of Sites 808 and 1173 in context of the 


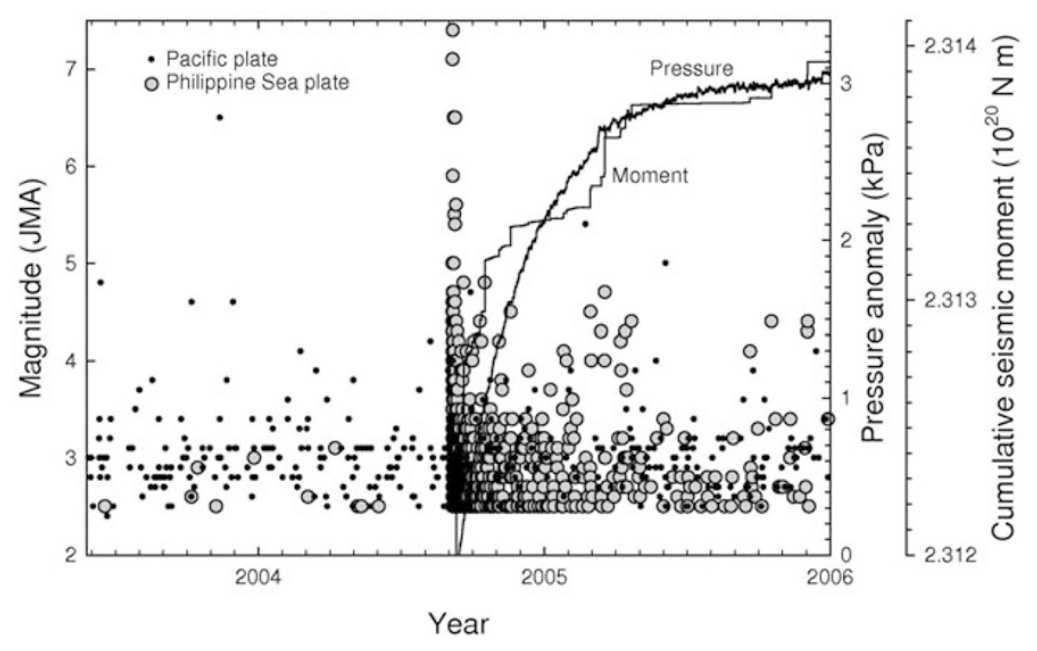

Fig. 8. Cumulative seismic moment estimated from aftershocks following the off-Kii earthquakes of September, 2005 (see Explanatory Notes section for details) compared to the post-seismic increase in pressure observed at Site 1173, screen 5. Small black circles show events in the same epicentral area but at much greater depths (c. $400 \mathrm{~km}$ ) within the subducting Pacific plate (see Fig. 1(a)).

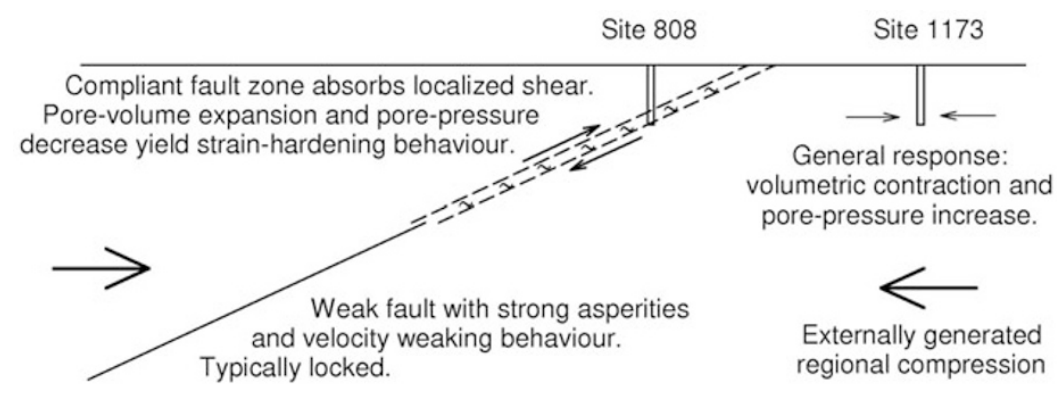

Fig. 9. Schematic cross section of a hypothetical subduction thrust fault, with the shallow part behaving dilatantly with thrust shear.

broad pattern of deformation predicted by the dislocation model (Fig. 1(b)), it is unlikely that the two sites experienced opposite co-seismic stress. It is more reasonable to conclude that the contrasting response at Site 808 is something that is peculiar to the decollement. One possible explanation is suggested in the interpretive cross-section in Fig. 9, in which a weak fault is shown cutting a medium of otherwise homogeneous properties. In this schematic section, cross-margin shortening (vectors, Fig. 1(b)) loads the section to cause regional contraction (as witnessed at Site 1173), but the particular properties of the fractured material in the decollement zone lead to pore-volume expansion under shear. Carried to a greater degree, this behaviour might produce sliding stability along the seaward part the subduction decollement, which is consistent with the behaviour inferred from a number of observations and theoretical considerations (Wang and $\mathrm{Hu}, 2006$; Wang and $\mathrm{He}$, 2008). While weak, the fault zone would strengthen with shear deformation as a consequence of falling fluid pressure and rising effective normal stress. This could augment any intrinsic velocity-strengthening behaviour of the shallow fault-zone material.

Response to the deformation associated with the offMuroto VLF earthquake swarm in 2003 is perplexing, but it could lend further insight into the behaviour of the decollement zone material. In this instance, cross-margin extension is suggested by the negative steps in pressure at Site
1173 (Figs. 2, 4), and the sense of shear at the decollement at Site 808 would have been opposite to that at the time of the off-Kii event. The rise in fluid pressure in the decollement at the time of the off-Muroto VLF event (Fig. 4) and the fall at the time of the off-Kii event (Fig. 3) may have been consequences of the deformation of a structural fabric that experiences porosity gain when sheared normally, and porosity loss when relaxed or sheared in reverse. This behaviour may be in some way analogous to that seen in velocity-stepping shear experiments, when expansion and contraction (and simultaneous increases and decreases in friction) of sheared granular material are seen at the times of shear-velocity increases and decreases, respectively (e.g., Mair and Marone, 1999; Rathbun et al., 2008).

\section{Conclusions}

Long-term CORK formation-fluid pressure records from ODP Site 1173, located on the Philippine Sea plate, offshore central Japan, display transients that are inferred to reflect co- and post-seismic strain associated with an intraslab earthquake sequence in the subducting Philippine Sea plate off Kii Peninsula in 2004. If our pressure-based estimates of strain are correct, the distal co-seismic contractional strain (and inferred stress change) is a factor of six larger than predicted by a dislocation model that assumes a total dislocation moment equal to the seismic moment. Post-seismic strain estimated from a continuing rise in pres- 
sure is larger still, and grows over the course of a year by an amount that exceeds the strain suggested by the total accumulation of seismic moment by a factor of nearly twenty. A large proportion of strain must occur aseismically.

Co-seismic pressure changes observed at the time of a deformation event off Cape Muroto in 2003 were opposite to those contemporary with the off-Kii event. The contrasting signs of the pressure transients seen at the times of the off-Kii and off-Muroto seismogenic events are consistent with the location of Site 1173 relative to the estimated areal distributions of dislocation strain, with the co-seismic changes being negative when volumetric strain is expansional (the off-Muroto event) and positive when strain is contractional (off-Kii). This leads to the inference that the changes in pressure at the time of both events reflect static elastic strain, not changes in the state or properties caused by dynamic strain induced by seismic waves.

Observations at the level of the decollement at ODP Site 808 , located $13 \mathrm{~km}$ landward of Site 1173 at the toe of the Nankai accretionary prism, reveal opposite senses of co-seismic pressure response (relative to Site 1173) to the off-Muroto and off-Kii events. We believe that this anomalous sense of pressure change reflects the behaviour of the thrust fault zone, where the granular fabric or fracture network expands or contracts when sheared or relaxed, respectively. If this behaviour operates in instances of greater thrust slip, then this shallow part of the subduction fault would strengthen, and thus resist seismic rupture.

Acknowledgments. We thank the Ocean Drilling Program for ongoing support for long-term borehole monitoring experiments, T. Pettigrew, R. Meldrum, and R. Macdonald for engineering assistance, and the pilots and crews of the submersible Shinkai 6500 and the remotely-operated vehicles Kaiko $12 \mathrm{k}$ and Kaiko $7 \mathrm{k}$ and the captains and crews of the JAMSTEC Research Vessels Kairei and Yokosuka for their capable support during site visits. Financial support has been provided by the U.S. National Science Foundation, the Geological Survey of Canada, and the Japanese Agency for Marine-Earth Science and Technology. GSC contribution no. 4711.

\section{Appendix A. Explanatory Notes}

In the case of the off-Kii earthquakes, the moment tensor for the largest event along with the distribution of aftershocks (Ito et al., 2005; Park and Mori, 2005; Figs. 1(a), 1(b)), provide constraints on the orientation and area of the rupture and the magnitude and direction of the slip used for estimating strain in Fig. 1(b). Parameters include: epicentral location: $33.18^{\circ} \mathrm{N}, 137.07^{\circ} \mathrm{E}$; strike $=240^{\circ}$, dip $=$ $60^{\circ}$, rake $=90^{\circ}$ (reverse fault, dipping NNW); hypocentral depth $=15 \mathrm{~km}$, length $=40 \mathrm{~km}$, width $=15 \mathrm{~km}$. With these fault dimensions, an assumed shear modulus = $30 \mathrm{GPa}$, and a seismic moment $M_{\mathrm{o}}=1.69 \times 10^{20} \mathrm{~N} \mathrm{~m}$, a slip $\approx 9 \mathrm{~m}$ is estimated. Magnitudes and mechanisms shown in Fig. 1(a) are solutions of the National Research Institute for Earth Science and Disaster Prevention (NIED). Earthquake magnitudes in Fig. 8 are ones determined by the Japanese Meteorological Agency (JMA), whose catalog for local events extends to lower magnitudes $(M=2.5)$ than those of other standard catalogs, and the cumulative moment was calculated using a standard relationship $M_{\mathrm{w}}=\left(\log _{10} M_{\mathrm{o}}-9.1\right) / 1.5$. Data were extracted from the
International Seismological Centre (ISC) earthquake cata$\log$ (http://www.isc.ac.uk/search/index.html).

\section{References}

Ashi, K., M. Okubo, H. Ishii, H. Aoki, T. Yamauchi, Y. Kitagawa, N. Koizumi, and S. Azuma, Co-seismic strain-steps associated with the 2004 off the Kii peninsula earthquakes observed with Ishii-type borehole strainmeters and quartz-tube extensometers, Earth Planets Space, 57, 309-314, 2005.

Bilek, S. and T. Lay, Rigidity variations with depth along interplate megathrust faults in subduction zones, Nature, 400, 443-446, 1999.

Bourlange, S., L. Jouniaux, and P. Henry, Data report: Permeability, compressibility, and friction coefficient measurements under confining pressure and strain, Leg 190, Nankai Trough, in Proc. ODP Sci. Results, edited by H. Mikada, G. Moore, A. Taira, K. Becker, J. Moore, and A. Klaus, 190/196, 1-16 (CD-ROM), 2005.

Davis, E. E. and K. Becker, On the fidelity of "CORK" borehole hydrologic observatory pressure records, Sci. Drill., 5, 54-59, 2007.

Davis, E. E., K. Wang, R. Thomson, K. Becker, and J. Cassidy, An episode of seafloor spreading and associated plate deformation inferred from crustal fluid pressure transients, J. Geophys. Res., 106, 21,953-21,963, 2001.

Davis, E. E., K. Becker, K. Wang, K. Obara, Y. Ito, and M. Kinoshita, A discrete episode of seismic and aseismic deformation of the Nankai trough subduction zone accretionary prism and incoming Philippine Sea plate, Earth Planet. Sci. Lett., 242, 73-84, 2006.

Elkhoury, J. E., E. Brodsky, and D. Agnew, Seismic waves increase permeability, Nature, 441, 1135-1138, 2006.

Gamage, K. and E. Screaton, Data report: Permeabilities of Nankai accretionary prism sediments, in Proc. ODP Sci. Results, edited by $\mathrm{H}$. Mikada, G. Moore, A. Taira, K. Becker, J. Moore, and A. Klaus, 190/196, 1-22 (CD-ROM), 2005.

Hashimoto, M., K. Onoue, F. Ohya, Y. Hoso, K. Segawa, K. Sato, and Y. Fujita, Crustal deformation in Kii Peninsula associated with the SE off the Kii peninsula earthquake sequence of September 5, 2004 derived from dense GPS observations, Earth Planets Space, 57, 185-190, 2005.

Hayakawa, T., T. Furuma, and Y. Yamanaka, Simulation of strong ground motions caused by the 2004 off the Kii peninsula earthquakes, Earth Planets Space, 57, 191-196, 2005.

Hofton, M. A. and G. Foulger, Postrifting anelastic deformation around the spreading plate boundary, north Iceland 1. Modeling of the 1987-1992 deformation field using a viscoelastic Earth structure, J. Geophys. Res., 101, 25,403-25,421, 1996.

Imakiire, T., S. Ozawa, H. Yarai, T. Nishimura, and H. Suito, Crustal deformation by the Southeast-off Kii Peninsula earthquake, Bull. Geogr. Surv. Inst., 53, 51-56, 2006.

Ito, Y., T. Matsumoto, H. Kimura, H. Matsubayashi, K. Obara, and S. Sekiguchi, Spatial distribution of centroid moment tensor solutions for the off Kii peninsula earthquakes, Earth Planets Space, 57, 351-356, 2005

Jaeger, J. C. and N. G. W. Cook, Fundamentals of Rock Mechanics, Chapman and Hall Ltd., London, 1969.

Kastner, M., K. Becker, E. Davis, A. Fisher, H. Jannasch, E. Solomon, and G. Wheat, New insights into the hydrogeology of the oceanic crust through long-term monitoring, Oceanogr., 19, 46-57, 2006.

Mair, K. and C. Marone, Friction of simulated faulte gouge for a wide range of velocities and normal stresses, J. Geophys. Res., 104, 28,89928,914, doi:10.1029/1999JB00279, 1999.

Matsumoto, H. and H. Mikada, Fault geometry of the 2004 off the Kii peninsula earthquake inferred from offshore pressure waveforms, Earth Planets Space, 57, 161-166, 2005.

Mikada, H., K. Becker, J. Moore, A. Klaus, and the shipboard scientific party, Proc. ODP Init. Repts., 196, CD-ROM, 2002.

Nakamula, S., M. Takeo, T. Yamada, M. Shinohara, and T. Kanazawa, Shallow low-frequency tremor in the accretionary prism along the Nankai Trough, Japan, Geophys. Res. Lett., 2008 (in review).

Obara, K. and Y. Ito, Very low frequency earthquakes excited by the 2004 off the Kii peninsula earthquakes: A dynamic deformation process in the large accretionary prism, Earth Planets Space, 57, 321-326, 2005.

Okada, Y., Internal deformation due to shear and tensile faults in a half space, Bull. Seismol. Soc. Am., 82, 1,018-1,040, 1992.

Okubo, M., Y. Asai, H. Aoki, and H. Ishii, The seismological and geodetical roles of strain seismogram suggested from the 2004 off the Kii peninsula earthquakes, Earth Planets Space, 57, 303-308, 2005. 
Park, S. and J. Mori, The 2004 sequence of triggered earthquakes off the Kii Peninsula, Japan, Earth Planets Space, 57, 315-320, 2005.

Pollitz, F. F., Transient rheology of the upper mantle beneath central Alaska inferred from the crustal velocity field following the 2002 Denali earthquake, J. Geophys. Res., 110, B08407, doi:10. 1029/2005JB003672, 2005.

Pollitz, F. F., C. Wicks, and W. Thatcher, Mantle flow beneath a continental strike-slip fault: Postseismic deformation after the 1999 Hector Mine earthquake, Science, 293, 1814-1818, 2001.

Rathbun, A. P., C. Marone, R. Alley, and S. Anandakrishnan, Laboratory study of the frictional rheology of sheared till, J. Geophys. Res., 113, F02020, doi:10.1029/2007JF000815, 2008.

Sakai, S., T. Yamada, M. Shinohara, H. Hagiwara, T. Kanazawa, K. Obana, S. Kodaira, and Y. Kaneda, Urgent aftershock observation of the 2004 off the Kii Peninsula earthquake using ocean bottom seismometers, Earth Planets Space, 57, 363-368, 2005.

Vidale, J. E. and H. Houston, The depth dependence of earthquake duration and implications for rupture mechanisms, Nature, 35, 45-47, 1993.
Wang, C.-Y., L. Cheng, C. Chin, and S. Yu, Coseismic hydrologic response of an alluvial fan to the 1999 Chi-Chi earthquake, Taiwan, Geology, 29, 831-834, 2001.

Wang, K., Applying fundamental principles and mathematical models to understand processes and estimate parameters, in Hydrogeology of the Oceanic Lithosphere, edited by E. E. Davis and H. Elderfield, 376-413, Cambridge University Press, Cambridge, 2004.

Wang, K. and Y. Hu, Accretionary prisms in subduction earthquake cycles: the theory of dynamic Coulomb wedge, J. Geophys. Res., 111, B06410, 2006.

Wang, K. and J. He, Effects of frictional behaviour and geometry of subduction fault on coseismic seafloor deformation, Bull. Seismol. Soc. Am., 98, 571-579, 2008.

E. Davis (e-mail: edavis@nrcan.gc.ca), K. Becker, K. Wang, and M. Kinoshita 